\title{
OS DISCURSOS EMPRESARIAIS E A RELAÇÃO DE DOMINAÇÃO SIGNIFICADA NO CONSENSO
}

\author{
MARIA ISABEL BRAGA SOUZA ${ }^{1}$ \\ Programa de Pós-Graduação em Ciências da Linguagem \\ Faculdade de Filosofia, Ciências e Letras Eugênio Pacelli \\ Universidade do Vale do Sapucaí \\ Av. Pref. Tuany Toledo, 470 - 37550-000 - Pouso Alegre - MG - Brasil \\ isabelsouza.jornalista@gmail.com
}

\begin{abstract}
Resumo. Buscamos apontar alguns efeitos de sentido que atravessam as relações entre sujeitos e instituições. Nosso material de análise são textos institucionais da empresa Alcoa Alumínio S/A. Buscamos refletir sobre o modo como estes textos se constituem enquanto interlocução da empresa com seu público, organizando os sentidos que estão em circulação, instituindo relações e padrões em espaços discursivos específicos para que essas formulações possam se significar, produzindo consenso e evitando conflitos. As análises empreendidas estão ancoradas na Análise de Discurso de linha francesa, fundamentadas principalmente nos estudos de Michel Pêcheux e Eni Orlandi.
\end{abstract}

Palavras-chave. Análise de Discurso; discurso empresarial; relações de trabalho.

\begin{abstract}
We seek to point to some effects of meaning which cross the relations between subjects and institutions. The material analyzed consists of institutional texts of the company Alcoa Aluminum S/A. We seek to reflect on how these texts are constituted producing interlocution between the company and its staff, organizing senses that are in circulation, establishing relations and patterns in discursive spaces so that formulations can produce meaning, consensus and trying to prevent conflicts. The analysis undertaken are anchored in French discourse analysis, based mainly on the studies of Michel Pêcheux and Eni Orlandi.
\end{abstract}

Keywords. Discourse Analysis; business discourse; working relations.

\section{Considerações iniciais}

O poder se inscreve na junção entre linguagem e língua, ao passo que é por meio da linguagem que o homem se significa e usa da língua, uma forma específica de linguagem, para estruturar os enunciados e sentidos produzidos pela relação de significação entre locutores. Sendo um ser simbólico, o homem é constituído na/pela linguagem, o que torna possível externalizar seus dizeres, produzir sentidos, e, mais

\footnotetext{
${ }^{1}$ Mestranda em Ciências da Linguagem (PPGCL-UNIVÁS). Professora na UNIFAE (Centro Universitário das Faculdades Associadas de Ensino).
} 
especificamente, em nosso caso de análise, os discursos de poder no campo empresarial. Orlandi (2002) afirma que a língua, concebida na perspectiva discursiva como materialidade linguística, é o lugar da manifestação das relações de forças e de sentidos que refletem os confrontos ideológicos.

Através de materiais, em especial os de comunicação com o público, como discutiremos mais a frente, a empresa organiza os sentidos que estão em circulação, institui relações e padrões, inscrevendo-se em materialidades discursivas que refletem a imagem que ela faz de si para seu público e a imagem que faz do seu próprio trabalhador ${ }^{2}$.

As empresas criam espaços discursivos específicos para que suas formulações possam significar, projetando um modelo de organização, um padrão, produzindo consenso, como forma de evitar conflitos. Essa produção de coerência no discurso é uma forma de poder, já que o político também se faz presente na relação entre o que é dito e os sentidos que se farão compreender. Trazendo essa reflexão para os discursos empresariais, o analista pode entender os mecanismos de funcionamento desses enunciados que materializam o posicionamento da empresa e outras posturas que podem ser consideradas reguladoras.

Para a Análise de Discurso de linha francesa, o político nos discursos reflete a disputa entre os sentidos dentro de circunstâncias dadas. Foucault (1970) afirma que o discurso é dispersão e são as instituições que dão sentido a ele; o discurso é aberto e quem o ordena é o autor.

Nessa perspectiva, precisamos lembrar que a política está em oposição ao consenso; ela é plural, assim com os sentidos. Na relação entre política e consenso, o poder atua como "polícia", assim como considera Rancière (1995), cercando, organizando e estabilizando os sentidos em uma direção determinada. As instituições usam esse imaginário consensual para significar o poder de determinadas formas, como dominação, como ausência de diferença, como igualdade.

Essas diferentes formulações do poder, por exemplo, acontecem na relação do sujeito de direito com suas obrigações vivendo em sociedade, sendo controlado por leis e hierarquias. Para a $\mathrm{AD}$, esse sujeito é livre para agir, porém submisso à lei, interpelado pelo poder, pela evidência inscrita no discurso da ordem, produzindo senso de afinidade e camuflando o litígio. São o político e o ideológico discursivizados pelo viés empresarial que serão objetos de nossas análises.

\section{Análise do corpus}

Para uma análise do discurso empresarial, selecionamos recortes de alguns dos textos produzidos pela multinacional Alcoa Alumínio S/A. A empresa está presente em mais de trinta países e possui cerca de 60 mil funcionários. No Brasil, instalou-se em

\footnotetext{
${ }^{2}$ As considerações que aqui apresentamos são parte das análises que integram a dissertação de mestrado que está em desenvolvimento, e que se concentra nos estudos acerca dos efeitos de sentidos nas estratégias de comunicação empresarial. A pesquisa tem como materiais de leitura recortes de textos da multinacional Alcoa Alumínio S/A, disponibilizados pela empresa em diferentes meios (impresso, digital etc.).
} 
1965, possui escritórios, unidades de exploração e empreendimentos em nove diferentes Estados, atuando na produção do metal, desde a extração da bauxita até sua transformação em diversos produtos.

Um primeiro aspecto a se destacar é que a empresa nomeia seus funcionários, independentemente da posição hierárquica que ocupam, como "Alcoanos". Analisando o uso dessa regularidade nos textos produzidos para o público interno e externo da empresa, percebemos que há um esforço para nivelar os trabalhadores, de modo que todos os vinculados a mesma empresa tenham atitudes, repliquem posturas e posições ideológicas, como espelhos da organização.

Criando a categoria "Alcoanos", a empresa busca a padronização e quem não se inscreve nesta posição estará fora da parcela dos que, pelo imaginário, entendem ser iguais perante à organização. $\mathrm{O}$ termo pode ainda ser compreendido como um nome próprio, uma identificação, com a grafia da primeira letra maiúscula, assim como acontece na grafia dos nomes próprios em nossa sociedade. Os "Alcoanos" se conhecem, têm ideologia própria e se inscrevem na mesma posição.

Orlandi (2013) afirma que em todo discurso há tensão entre o mesmo e o diferente. Uma força que atua entre a paráfrase e a polissemia que, segundo a autora, são relações que trabalham o dizer. Há aí também a memória, pois quando dizemos algo produzimos um sentido em nossas palavras, mas elas já foram ditas, pertencem a uma rede de filiações e isto dá movimento, direções ao sujeito e aos sentidos. Pela paráfrase, há o deslizamento dos sentidos, um efeito metafórico, como compreende Orlandi (2012), e a possibilidade da produção de sentidos outros, "fala-se a mesma língua, mas se fala diferente" (ORLANDI, idem, p. 81).

Pelas paráfrases, podemos nos aproximar do modo de formulação da ideologia no discurso. Segundo Orlandi (2012), uma análise com possíveis deslizamentos pode revelar o que está silenciado, ausente no texto, e faz com que o analista seja capaz de remeter sua interpretação a outros sentidos. Ainda sobre o silêncio, como parte constitutiva dos discursos, Orlandi (2002) afirma que compreender o silêncio é explicitar o modo pelo qual ele significa, conhecer os processos de significação que ele põe em jogo, os seus modos de significar.

Assim, pensamos em deslizes possíveis para o termo "Alcoanos", apoiando-nos nos processos de formação de palavras através da sufixação. Elegemos as terminações: ano, -elo, -eiro, -ista, -ense e -ismo, subsidiando nossas análises nas denominações destes sufixos encontradas no dicionário Houaiss (2010). Na gramática, a sufixação é entendida como um processo que origina novas palavras através da soma de um elemento colocado depois do radical da palavra, sendo capaz de produzir derivações ou flexões, como de gênero (masculino e feminino) e número (singular e plural), por exemplo.

Iniciamos nossas análises, via efeito metafórico, a partir do sufixo "ano". No dicionário Houaiss, encontramos a seguinte denominação, e procuramos ainda por desdobramentos complementares a ela:-ano: origem, procedência: sergipano. Relação: republicano, freudiano. 
- Procedência: ato de proceder ou o seu efeito. Lugar de onde algo ou alguém provém; ponto de partida, origem. Característica do que tem base, fundamento. Procedente.

- Proceder: Ter como ponto de partida (um lugar); vir; provir. Ter seguimento; prosseguir, continuar. Ter certo comportamento, atitude, portar-se, agir. Mostrar-se verdadeiro. Ter origem, provir, derivar, ser descendente de; provir. Levar a efeito, realizar, fazer.

- Origem: ponto de partida; começo. Procedência; ascendência. Causa; razão. Já para os sufixos -elo, -eiro, -ista, -ense e -ismo, encontramos as seguintes definições:

- elo: 'diminuição': magrelo

- eiro: agente, profissão: jornaleiro. Árvore produtora: limoeiro. Quantificação: nevoeiro. Local, receptáculo: galinheiro, açucareiro. Origem, nacionalidade: brasileiro. Relação: verdadeiro.

- ista: seguidor, partidário: corporativista, governista. Profissão, ocupação: dentista, tenista. Origem: nortista.

- ense: relação de origem: cearense, circense, parisiense.

- ismo: doutrina, teoria: mercantilismo, socialismo. Atividade, prática esportiva: ciclismo, montanhismo. Qualidade: brasileirismo, heroísmo. Estado patológico: alcoolismo, paludismo.

Pelo efeito metafórico, propomos as seguintes derivações para a palavra, além daquela que já é nosso objeto de análise: Alcoano; Alcoelo; Alcoeiro; Alcoista; Alcoense e Alcoismo. Essas derivações nos remetem a sentidos diferentes.

A denominação Alcoano surge como um adjetivo pátrio, de pertencimento. Essa mobilização do sufixo nos leva a interpretações de procedência, origem, a uma relação ente os pares. Indo mais além, o fato de este sufixo trazer o sentido de pertencimento e procedência pode ser entendido neste contexto como origem, ponto de partida, de derivarse, de ser descendente de. E para arrematar nossa interpretação, a palavra origem também é muito significativa nessa descrição e é até mesmo sinônima para a relação de começo, de ponto de partida, de ser originário de.

Esses sentidos já não são os mesmos partindo da sufixação que origina outras formulações, como propomos. O sufixo -elo, segundo o dicionário, dá sentido diminutivo; -eiro, embora também tenha sentido de pertencimento, tem maior significação entre profissões, por exemplo: jornaleiro, engenheiro, cozinheiro, porteiro, sapateiro e outras derivações que originam denominação para trabalhos braçais. Este sufixo ainda nos remete à brasileiro, povo colonizado, submisso a outra nação colonizadora.

O sufixo -ista também significa relações e origem, local e profissão; -ense, tem uma proximidade maior com os adjetivos pátrios e sentidos de pertencimento; e para finalizarmos, o sufixo -ismo, que remete a outras significações como teorias, atividades, doutrinas etc. O que ressoa sentido sobre "Alcoanos", se pensarmos na relação e no modo como a empresa se coloca. O termo "Alcoismo" poderia sugerir uma doutrinação, não 
evidente, mas que está significada no termo "Alcoanos" e que silencia as relações de trabalho, analisando a maneira como a empresa se inscreve em seus discursos.

A língua nos permite formar diversas palavras que têm sentidos que precisam ser considerados na/pela história de significação que carregam. Com esta nomeação "Alcoano", nesse sentido de pertencimento, de origem, a empresa consegue materializar pelo discurso ideais que refletem o seu próprio posicionamento no mundo capitalista. É interpelando o sujeito dessa maneira, silenciando as relações de trabalho e inscrevendo o sujeito trabalhador como parte integrante de um todo, que a empresa unifica as ações em prol de um propósito maior: o da permanência no mercado. E, para isso, motiva os funcionários não só na realização do trabalho em si, mas na participação em programas comunitários, projetos e outras iniciativas que asseguram o reconhecimento da multinacional no mercado, agregando valor à marca, aos produtos e à imagem dela perante o público.

Vejamos alguns recortes do website da empresa. O primeiro, vinculado ao item Política, na aba Institucional. Neste item, a empresa apresenta seus princípios em relação às áreas de saúde, segurança e meio ambiente. ${ }^{3}$

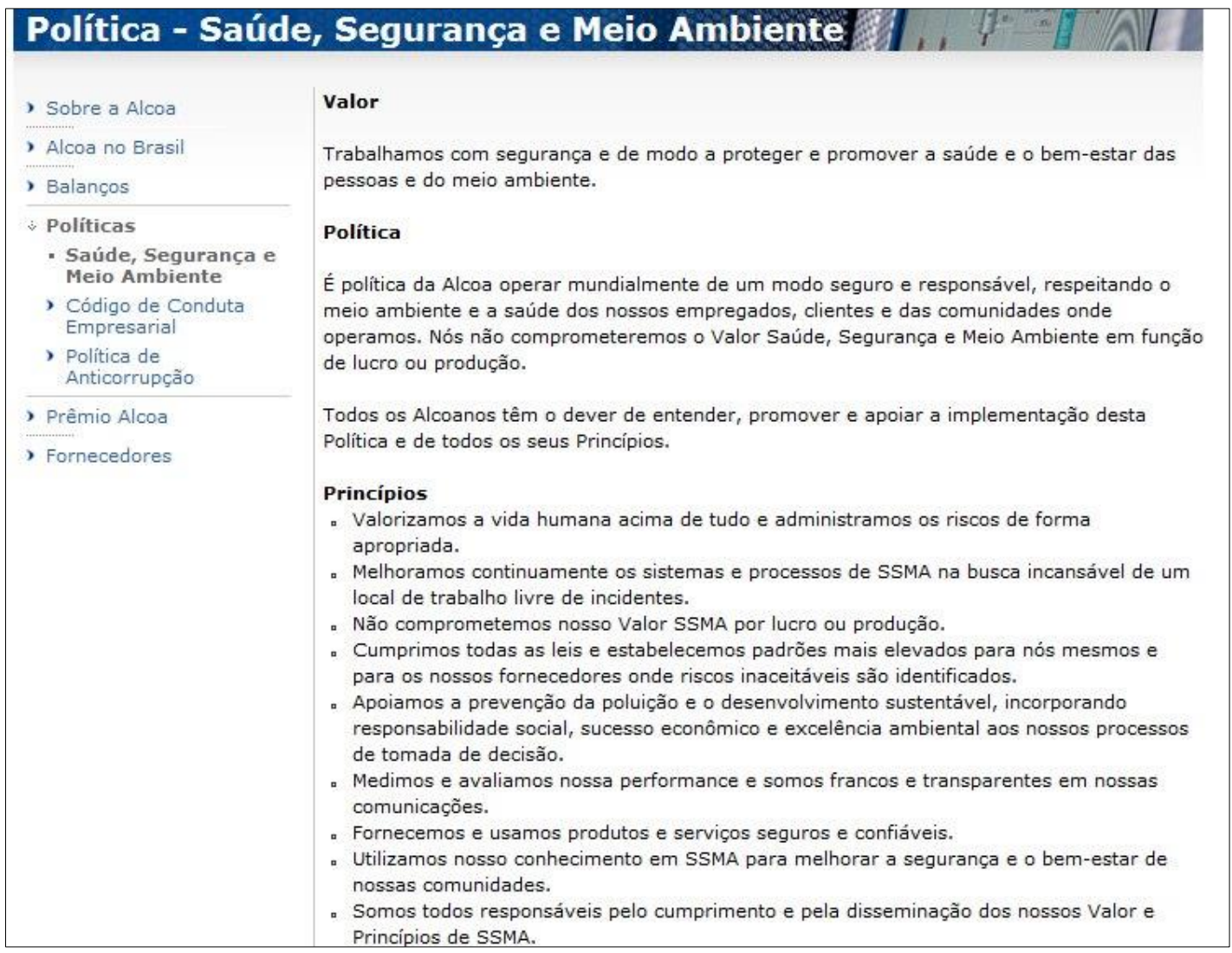

Figura 1. Localização do recorte número 1 (abaixo), alocado no site da empresa.

\footnotetext{
${ }^{3}$ Disponível em <https://www.alcoa.com/brasil/pt/info_page/politica_ssma.asp >; acesso em jun. 2016.
} 


Recorte 1
Valor
Trabalhamos com segurança e de modo a proteger e promover a saúde e o bem-estar
das pessoas e do meio ambiente.
Política
É política da Alcoa operar mundialmente de um modo seguro e responsável,
respeitando o meio ambiente e a saúde dos nossos empregados, clientes e das
comunidades onde operamos. Nós não comprometeremos o Valor Saúde,
Segurança e Meio Ambiente em função de lucro ou produção.
Todos os Alcoanos têm o dever de entender, promover e apoiar a implementação
desta Política e de todos os seus Princípios.
Princípios
Valorizamos a vida humana acima de tudo e administramos os riscos de forma
apropriada
Melhoramos continuamente os sistemas e processos de SSMA na busca incansável
de um local de trabalho livre de incidentes.
Não comprometemos nosso Valor SSMA por lucro ou produção.
Cumprimos todas as leis e estabelecemos padrões mais elevados para nós mesmos
e para os nossos fornecedores onde riscos inaceitáveis são identificados.
Apoiamos a prevenção da poluição e o desenvolvimento sustentável, incorporando
responsabilidade social, sucesso econômico e excelência ambiental aos nossos
processos de tomada de decisão.
Medimos e avaliamos nossa performance e somos francos e transparentes em nossas
comunicações.
Fornecemos e usamos produtos e serviços seguros e confiáveis.
Utilizamos nosso conhecimento em SSMA para melhorar a segurança e o bem-estar
de nossas comunidades.
Somos todos responsáveis pelo cumprimento e pela disseminação dos nossos Valor
e Princípios de SSMA.

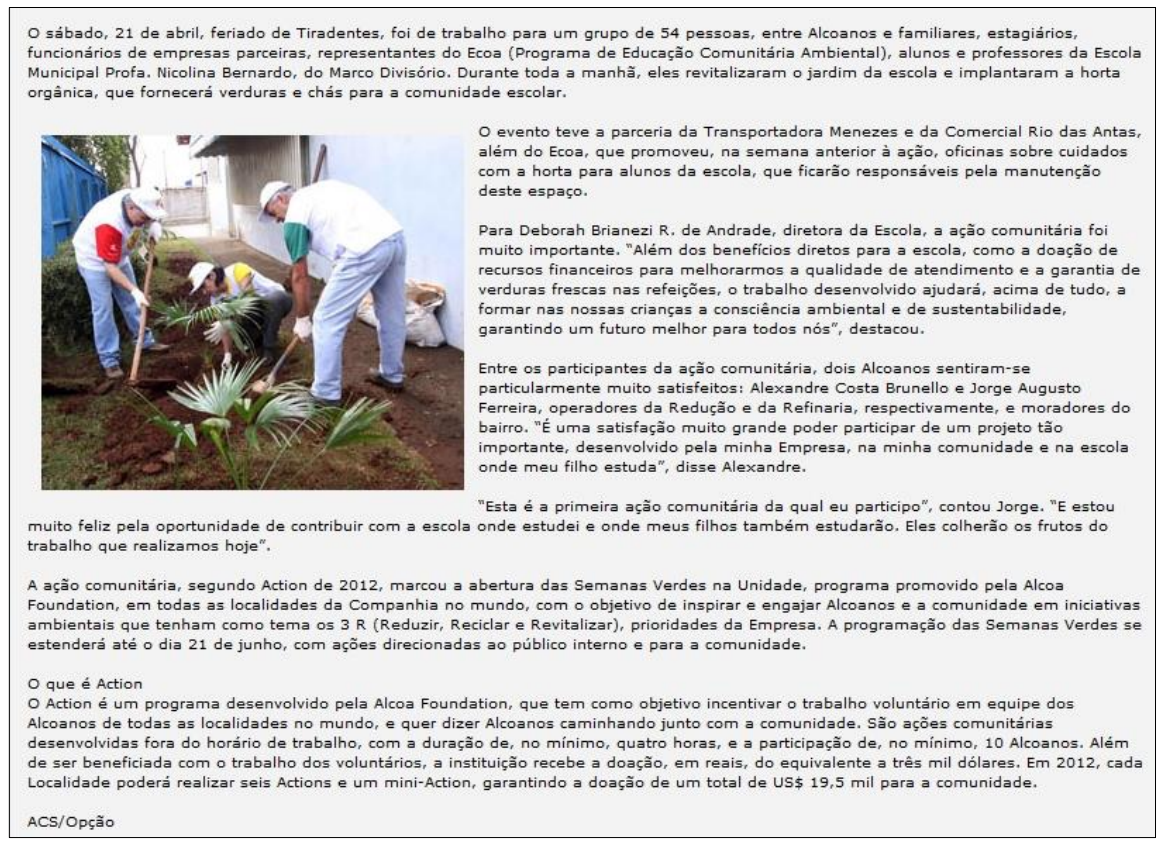

Figura 2. Localização do recorte 2 (abaixo). Publicação do release da empresa em um site de notícias da região de Poços de Caldas-MG.

\footnotetext{
${ }^{4}$ SSMA: saúde, segurança e meio ambiente.
} 
Vejamos agora um outro recorte (Recorte 2), em que a nomenclatura "Alcoanos" aparece em um texto enviado à imprensa. Neste material, a Assessoria de Imprensa da multinacional divulga informações sobre a atuação dos "Alcoanos" em ações de voluntariado. Os releases estão alocados no ícone Imprensa, item Releases. No Brasil, essas iniciativas são oriundas do Instituto Alcoa, fundado em 1990, com o objetivo de aproximar a empresa das comunidades onde atua.

\begin{abstract}
Recorte 2
Ação comunitária de Alcoanos implanta horta orgânica em escola

O sábado, 21 de abril, feriado de Tiradentes, foi de trabalho para um grupo de 54 pessoas, entre Alcoanos e familiares, estagiários, funcionários de empresas parceiras, representantes do Ecoa (Programa de Educação Comunitária Ambiental), alunos e professores da Escola Municipal Profa. Nicolina Bernardo, do Marco Divisório. Durante toda a manhã, eles revitalizaram o jardim da escola e implantaram a horta orgânica, que fornecerá verduras e chás para a comunidade escolar.

O evento teve a parceria da Transportadora Menezes e da Comercial Rio das Antas, além do Ecoa, que promoveu, na semana anterior à ação, oficinas sobre cuidados com a horta para alunos da escola, que ficarão responsáveis pela manutenção deste espaço.

Para Deborah Brianezi R. de Andrade, diretora da Escola, a ação comunitária foi muito importante. "Além dos benefícios diretos para a escola, como a doação de recursos financeiros para melhorarmos a qualidade de atendimento e a garantia de verduras frescas nas refeições, o trabalho desenvolvido ajudará, acima de tudo, a formar nas nossas crianças a consciência ambiental e de sustentabilidade, garantindo um futuro melhor para todos nós", destacou.

Entre os participantes da ação comunitária, dois Alcoanos sentiram-se particularmente muito satisfeitos: Alexandre Costa Brunello e Jorge Augusto Ferreira, operadores da Redução e da Refinaria, respectivamente, e moradores do bairro. "É uma satisfação muito grande poder participar de um projeto tão importante, desenvolvido pela minha Empresa, na minha comunidade e na escola onde meu filho estuda", disse Alexandre.

"Esta é a primeira ação comunitária da qual eu participo", contou Jorge. "E estou muito feliz pela oportunidade de contribuir com a escola onde estudei e onde meus filhos também estudarão. Eles colherão os frutos do trabalho que realizamos hoje".

A ação comunitária, segundo Action de 2012, marcou a abertura das Semanas Verdes na Unidade, programa promovido pela Alcoa Foundation, em todas as localidades da Companhia no mundo, com o objetivo de inspirar e engajar Alcoanos e a comunidade em iniciativas ambientais que tenham como tema os 3 R (Reduzir, Reciclar e Revitalizar), prioridades da Empresa. A programação das Semanas Verdes se estenderá até o dia 21 de junho, com ações direcionadas ao público interno e para a comunidade.
\end{abstract}

\title{
O que é Action
}

O Action é um programa desenvolvido pela Alcoa Foundation, que tem como objetivo incentivar o trabalho voluntário em equipe dos Alcoanos de todas as localidades no mundo, e quer dizer Alcoanos caminhando junto com a comunidade. São ações comunitárias desenvolvidas fora do horário de trabalho, com a duração de, no mínimo, quatro horas, e a participação de, no mínimo, 10 Alcoanos. Além de ser beneficiada com o trabalho dos voluntários, a instituição recebe a doação, em reais, do equivalente a três mil dólares. Em 2012, cada Localidade poderá realizar seis Actions e um mini-Action, garantindo a doação de um total de US\$19,5 mil para a comunidade. ${ }^{5}$

\footnotetext{
${ }^{5}$ Textos disponíveis em 〈http://www.alcoa.com/brasil/pt/info_page/news releases.asp $>$, e em <http://www.poçosnet.com.br/noticia.php?id=2282>; acesso em jun. 2016.
} 
Através do Instituto Alcoa vários outros projetos nessa mesma linha são realizados, entre eles os da Alcoa Foundation, não só no Brasil, mas também em outros países de atuação da empresa. A Alcoa Foundation tem o objetivo de desenvolver iniciativas de voluntariado, com a participação dos funcionários, em ações de apoio às comunidades onde a Alcoa está presente.

Em ambos os recortes acima (1 e 2), podemos notar a palavra "Alcoanos" como forma de significar os funcionários da empresa. No primeiro, são eles os responsáveis por assegurar a aplicabilidade dos objetivos da política de segurança, atuando em consenso com a empresa, integrando-a, fazendo parte dela. Há produção de um efeito de coesão, uma classe de sujeitos que se integram, se relacionam e estabelecem uma representatividade para com a empresa, tornam-se uma extensão dela.

Os "Alcoanos" têm competência para disseminar a postura da empresa entre eles próprios; é o poder que, como água, inunda os funcionários, para que corroborem com um propósito. Poderíamos aqui citar a noção de texto fundador, como propõe a Análise de Discurso, onde a regulação é replicada, mas não há uma reflexão por parte do sujeito de que modo surgiu e como ela se inscreve no enunciado.

Remetendo à Barthes (1977, p. 03) "a linguagem é uma legislação, a língua é seu código. Não vemos o poder que reside na língua, porque esquecemos que toda língua é uma classificação e, que toda classificação é opressiva". Ainda nesse sentido, do poder como água que inunda, Barthes (1977, p. 04), afirma que "assim que ela é proferida, mesmo que na intimidade mais profunda do sujeito, a língua entra a serviço de um poder, nela, infalivelmente, duas rubricas se delineiam: a autoridade da asserção, o gregarismo da repetição [...] Na língua, portanto, servidão e poder se confundem inelutavelmente".

Ainda no primeiro recorte, destacamos os enunciados presentes no seguinte fragmento: "É política da Alcoa operar mundialmente de um modo seguro e responsável, respeitando o meio ambiente e a saúde dos nossos empregados, clientes e das comunidades onde operamos. Nós não comprometeremos o Valor Saúde, Segurança e Meio Ambiente em função de lucro ou produção. [...] Cumprimos todas as leis e estabelecemos padrões mais elevados para nós mesmos e para os nossos fornecedores onde riscos inaceitáveis são identificados".

Ao depararmos-nos com "nós", perguntamo-nos: a quem o "eu" do discurso se associa? $\mathrm{O}$ uso da primeira pessoa do plural nestes pontos em destaque mostra a denegação da empresa ao inscrever o funcionário em um discurso onde ela aparece em primeiro plano, ou seja, o "nós", não no sentido coletivo, mas de controle, de posse. O "nós não comprometeremos" refere-se à empresa: anula-se o funcionário e os demais envolvidos. Embora haja um esforço em tornar coletivas e distribuídas as responsabilidades, neste caso, da política da empresa, ou seja, dos seus valores, ela fala por si, o "nós" é o "eu" da empresa apresentado de forma dilatada (MAREGA, 2008) e não agregadora.

No segundo recorte que trouxemos para análise, temos um texto veiculado em uma dimensão discursiva diferente do da primeira. Além de estar disponível no ambiente on-line, o enunciado também é enviado para a mídia. No recorte 2 , destinado ao público externo, dar publicidade à iniciativa é uma forma de fortalecer a imagem da empresa, 
valorizar o funcionário e novamente afirmar que "Alcoanos" têm posturas diferentes, são diferentes dos funcionários de outras empresas.

O ser "Alcoano" implica em um consenso de ajuda mútua, de felicidade pela ação voluntária, de empresa boa para se trabalhar e que não visa só lucros, mas pensa também no próximo, nos diversos públicos que a circundam. Estes diferentes públicos podem ser compreendidos por público "interno" àqueles que têm ligações diretas com a empresa: funcionários, gestores, acionistas etc; e "externo", os que podem ou não ter ligações diretas: sociedade, vizinhança, sindicatos, ONGs, clientes, fornecedores, imprensa etc.

Essa noção de ajuda mútua, de compaixão ao próximo pode ser até mesmo comparada ao discurso religioso, onde há alguém que fala, ocupando uma determinada posição; e esse enunciado não é discutido, coloca-se em prática, sem que haja manifestação em contrário, tomando-o como algo transparente, evidente.

A Alcoa não aparece em primeiro plano nos dois textos apresentados. Usa do termo "Alcoanos" para direcionar aos funcionários os créditos pela manutenção dos ideais da empresa e das ações na comunidade de forma voluntária. É o discurso institucional sendo representado através dessa nomenclatura. Os enunciados produzem a noção de consenso para os públicos de dentro e fora da empresa. E sobre isso Orlandi afirma que

[...] todo sujeito interpreta a partir de um dispositivo ideológico que o faz interpretar de uma maneira e não de outra. Pelo processo de identificação, como sabemos, o sujeito se inscreve em uma formação discursiva para que suas palavras tenham sentido, e isto lhe aparece como natural, como o sentido lá, transparente. Ele não reconhece o movimento da interpretação, ao contrário, ele se reconhece nele. Ele se reconhece nos sentidos que produz. (ORLANDI, 2015, p. 30)

Ao se depararem com a nomenclatura "Alcoanos", os funcionários silenciam o "eu", o indivíduo se oculta para se inscrever nestes enunciados mercadológicos. Esse silenciamento, ocasionado pelo consenso e domínio, faz com que os indivíduos/funcionários se nivelem ao padrão da empresa, às suas ideologias, se assujeitando à formação discursiva do capital.

No discurso da Alcoa, quem está inserido neste ambiente consensual é competente por agir dessa maneira e não de outra; inscreve-se os funcionários em uma visão de dentro para fora, lugar imaginário onde eles são diferentes, quando comparados a outros trabalhadores, de outras empresas. Esse imaginário é reflexo de como a multinacional se significa, evidenciando que quem não cumpre o que está estabelecido é desqualificado. Nossa formação social nos remete ao capital e a denominação "Alcoanos" produz um efeito de verdade, dá existência a algo inexistente: o coletivo da empresa inventado, o "nós" Alcoa.

O consenso produzido pelo imaginário é o que garante, de certo modo, a manutenção do jogo capitalista, que está centralizado nos interesses da empresa. É o efeito identificatório do "bom sujeito" que aparece nas relações de trabalho da atual sociedade; e, sobre isso, Amaral aponta que 
o sujeito universal, que orienta o discurso no campo do trabalho, é o capital, o que dá voz ao sujeito do discurso mercadológico. Nesta prática discursiva do trabalho, o "bom sujeito" é interpelado pelo interdiscurso do engajamento, do empreendedorismo, da competência, da responsabilidade, do sucesso, que determina a Formação Discursiva Mercadológica. O "bom sujeito" faz parte de uma equipe, participa de grupo, executa trabalho voluntário, possui vários títulos e, por tudo isso, expõe um bom currículo. (AMARAL, 2008, p. 02)

Tanto para o público interno, quanto para o externo, ações de responsabilidade social podem ser compreendidas das mais variadas formas, mas há uma memória discursiva que proporciona valor à empresa e aos seus produtos quando ela está associada a essas iniciativas de bem comum, incluindo a sociedade, os seus funcionários, o meio ambiente etc. Sobre esse posicionamento estratégico da empresa, Reginato e Pozza (2013, p. 143) apontam que "tornou-se praticamente uma exigência mercadológica que os valores da responsabilidade social e da sustentabilidade sejam incorporados pela cultura da organização e comunicados efetivamente a seus públicos”.

\section{Conclusão}

Os enunciados nos dois recortes têm como um dos públicos de direcionamento estratégico a sociedade de modo geral, e é ela, a sociedade, produtora e propagadora de opiniões e posicionamentos. Dessa forma, os textos são (res)significados segundo as interpretações do público, suas formações discursivas e sentidos que se podem compreender a partir dos textos.

Se o discurso é efeito de sentido entre locutores (PÊCHEUX, 1969), esses efeitos do discurso institucional se dão uma vez que os sujeitos se encontram em determinada circunstância e são afetados por memórias discursivas que também estão presentes nas condições de produção dos enunciados da empresa. O termo "Alcoano" legitima a multinacional, produzindo um imaginário do bom lugar para se trabalhar, da boa empresa, dos bons produtos para se consumir, de uma instituição parceira da sociedade, preocupada com o social e o ambiental. É o poder justificado, atravessado pelos parâmetros capitalistas que fortemente estão nos textos da atualidade e são incorporados à empresa de modo que os diferentes públicos - interno e externo - também se signifiquem neste discurso, mesmo que não se deem conta disso.

\section{Referências bibliográficas}

AMARAL, M.V.B. O discurso do bom sujeito nas relações de trabalho. Disponível em $<$ http://www.anpoll.org.br/eventos/enanpoll2008/admin/exibe_resumo.php?CodResumo $=1286>$; acesso em 05 jun. 2015.

BARTHES, Roland. [1977] Aula. São Paulo: Cultrix, 2000. 
FOUCAULT, Michel. A ordem do discurso. São Paulo: Loyola, 2002.

HOUAISS, Antônio; VILLAR, Mauro de Salles. Minidicionário Houaiss da Língua Portuguesa. Rio de Janeiro: Objetiva, 2010.

MAREGA, Larissa Minuesa Pontes A categoria dêitica "nós" em uma elocução formal: breve análise de um caso. SIGNUM [Estudos da Linguagem], Programa de Pósgraduação em Estudos da Linguagem da Universidade Estadual de Londrina, Londrina, $\begin{array}{lllllll}\text { p. 151-165, } & \mathrm{n}^{\mathrm{o}} & 11 & (1), & 2008 . & \text { Disponível } & \mathrm{em}\end{array}$ <http://www.uel.br/revistas/uel/index.php/signum/article/viewFile/3088/2621>; acesso em set. 2015.

ORLANDI, E.; RODRIGUES, S.L. (Orgs.). Discurso e textualidade. $3^{\text {a }}$ ed. Campinas: Pontes, 2015.

ORLANDI, Eni. As formas do silêncio: no movimento dos sentidos. $5^{\mathrm{a}}$ ed. Campinas: Ed. da Unicamp, 2002.

PÊCHEUX, M. [1969] Análise Automática do Discurso. Em: GADET, F.; HAK, T. (Orgs.). Por uma análise automática do discurso: uma introdução à obra de Michel Pêcheux. Campinas: Editora da Unicamp, 1997.

RANCIÈRE, J. O desentendimento: política e filosofia. São Paulo: Editora 34, 1996.

REGINATO, Gisele Dotto; POZZA, Débora Flores Dalla. O discurso da responsabilidade social e da sustentabilidade na comunicação organizacional da Vale. REVISTA ORGANICOM, Escola de Comunicações e Artes da Universidade de São Paulo, São Paulo, p. 138-150, $\mathrm{n}^{\mathrm{o}} \quad 18, \quad 2013 . \quad$ Disponível em <http://www.revistaorganicom.org.br/sistema/index.php/organicom/article/view/578>; acesso em set. 2015.

$\begin{array}{lllll}\text { ALCOA } & \text { S/A } & \text { (Brasil). } & \text { Disponível }\end{array}$ <http://www.alcoa.com/brasil/pt/info_page/home.asp $>$; acesso em mai. 2015.

Artigo recebido em: janeiro de 2016.

Aprovado e revisado em: junho de 2016.

Publicado em: agosto de 2016

\section{Para citar este texto:}

SOUZA, Maria Isabel Braga. Os discursos empresariais e a relação de dominação significada no consenso. Entremeios [Revista de Estudos do Discurso], Seção Estudos, Programa de Pós-graduação em Ciências da Linguagem (PPGCL), Universidade do Vale do Sapucaí, Pouso Alegre (MG), vol. 13, p. 33-43, jan. - jun. 2016.

DOI: http://dx.doi.org/10.20337/ISSN2179-3514revistaENTREMEIOSvol13pagina33a43 